\title{
Levels of empathy in undergraduate emergency health, nursing, and midwifery students: a longitudinal study
}

This article was published in the following Dove Press journal:

Advances in Medical Education and Practice

II September 2014

Number of times this article has been viewed

\author{
Brett Williams' \\ Ted Brown ${ }^{2}$ \\ Malcolm Boyle' \\ Lisa McKenna ${ }^{3}$ \\ Claire Palermo ${ }^{4}$ \\ Jamie Etherington' \\ 'Department of Community \\ Emergency Health and Paramedic \\ Practice, ${ }^{2}$ Department of \\ Occupational Therapy, ${ }^{3} \mathrm{School}$ of \\ Nursing and Midwifery, Faculty \\ of Medicine, Nursing and Health \\ Sciences, Monash University-Peninsula \\ Campus, Frankston, ${ }^{4}$ Department \\ of Nutrition and Dietetics, Faculty \\ of Medicine, Nursing and Health \\ Sciences, Monash University-Berwick \\ Campus, Berwick, Vic, Australia
}

Purpose: This research examines the extent and nature of empathy among emergency health (paramedic), nursing, and midwifery students at one Australian university and investigates the longitudinal changes in empathy levels across the course of study.

Methods: First-, second-, and third-year students at Monash University completed the Jefferson Scale of Empathy-Health Professional (JSE-HP) in 2008, 2009, and 2010, and the resulting mean empathy scores were analyzed by course, year of course, year of study, age, and sex.

Results: Midwifery students were found to have higher empathy levels than nursing and emergency health students. Second- and third-year students scored higher than their counterparts in the first year. Empathy levels dipped in 2009 and rose in 2010. Students aged 26-30 years and 31-35 years recorded higher scores than their younger colleagues, and female students were found to be more empathic than their male counterparts.

Conclusion: The finding that empathy levels are relatively stable over the term of study contributes to the understanding of how empathy evolves over the course of study and offers insights into the importance of incorporating and promoting empathy in health care curricula.

Keywords: empathy, nursing, paramedics, midwifery, undergraduates

\section{Introduction}

Empathy is widely considered an essential cognitive and psychological attribute of health care professionals and is recognized as improving many aspects of health care practice including patient compliance; establishing rapport with patients and families; enhancing patient satisfaction, history taking, and clinical outcomes; and minimizing the rate of medical errors. ${ }^{1-5}$

Derived from the Greek word “empatheia”, meaning to understand someone else's feelings, empathy was first incorporated into the doctor-patient relationship in 1918 by Southard as a resource for facilitating diagnosis and therapeutics. ${ }^{3}$ Empathy, however, is an elusive concept and it is important to establish a solid working definition to avoid it becoming a murky and nebulous notion. If we consider empathy as something that can be taught and not simply a personality trait, then the differentiation between one's own experience and the experience of another is the decisive criterion for defining effective empathy. It is also important to distinguish between empathy, which involves an understanding of patients' experiences and the capacity to communicate that understanding, and sympathy, which is an emotional response to the patient's feelings and concerns. The sympathetic health professional may well care about their patients' suffering, but demonstrating sympathy alone can interfere with clinical objectivity and professional effectiveness. The empathic health care professional cares about understanding the 
quality of the patient's experience and has the capacity to communicate this understanding. ${ }^{6}$

Empathic statements provide patients with effective psychological support and allows the practitioner to move back to the aspects of the patient's condition that need treatment. ${ }^{7}$ The literature reveals a clear link between practitioner empathy and higher satisfaction rates among patients ${ }^{8-10}$ and the benefits for positive clinical outcomes. ${ }^{1,11,12}$ Acknowledging difficult and often painful situations creates a positive connection between the patient and his/her family and the health care provider. For example, even a simple statement such as "That must be very difficult for you" legitimizes the patient's reaction and reassures them the practitioner has understood the situation. The perspective-taking component has been described as a major dimension of empathy in patient care. ${ }^{4,11}$

It has been suggested that empathy in health care can be developed through basic and graduate professional education. Recently, educators are beginning to incorporate the development of empathic skills into health professional curricula to assist students in progressing toward higher levels of empathy and exhibiting empathic behaviors appropriately. ${ }^{2,4,12}$ However, the international evidence is that many students' ability to communicate empathy during in-depth clinical learning experiences is limited, with consequences for future clinical practice. ${ }^{13}$ Indeed, a recent meta-analysis of studies by researchers in the United States found that American college students generally have lower empathy levels than do students from previous generations. ${ }^{14}$ For health professional students in particular, this has serious implications, for not only are they incapable of demonstrating empathic behaviors, but many fail to even acknowledge the relevance of this vital skill in relation to their own future health care careers. ${ }^{2}$ The educational experience itself may be to blame, although social, economic, and generational factors may also have an influence. One remedy for improving the empathic tendencies of health care students is through the integration and application of appropriate teaching techniques and the engagement of students in experiential styles of learning., ${ }^{4-15}$

There is a wealth of previous research measuring empathy levels among specific health care groups (in particular, medical students and nurses in training), but there are few published papers measuring empathy levels extending across several health disciplines. To the best of our knowledge, there are no previously published longitudinal studies.

Studies of medical students typically show higher empathy scores in the early preclinical years of study than in later and final clinical years. Chen et al, ${ }^{19}$ in their investigation of medical students at one American university, found that empathy differed significantly between second- and third-year classes, corresponding to the first year of clinical training. Students with a preference for people-oriented specialties were also more likely to be female and more empathic than their colleagues who preferred technology-oriented specialties. The findings are similar to those of another, earlier study where students who chose core specialties such as family medicine and pediatrics scored higher than those in noncore specialties (for example, radiology) ${ }^{20} \mathrm{~A}$ significant decline in empathy levels during the course of study is also noted in nursing students. For example, Ward et $\mathrm{al}^{21}$ found a more pronounced decline in empathy among students exposed to clinical encounters and real patients, compared with nursing students in their first year of study, who spent most of their time in the laboratory setting.

In order to establish a baseline from which to begin promoting empathy among undergraduate health profession students, our study seeks to understand the extent and nature of empathy among emergency health (paramedic), nursing, and midwifery students at one Australian university. This longitudinal study investigates students' overall levels of empathy when they first begin studying and what impact, if any, their studies have on their empathy levels as they progress from the first year to the final year of their undergraduate degree. The findings will assist our understanding of the variation of empathy in undergraduate health courses and assist educators in curriculum renewal and coherence, and in developing strategies to increase students' ability to provide empathic care to patients and their families.

\section{Methods}

\section{Participants}

The participants were 948 emergency health (paramedic), nursing, and midwifery students enrolled in the first-, second-, and third-year undergraduate programs offered at Monash University during 2008-2010.

\section{Instrumentation}

In this longitudinal study, empathy is operationally defined by the Jefferson Scale of Physician Empathy (JSPE) and the Jefferson Scale of Empathy-Health Professional (JSE-HP) in which empathy is a predominantly cognitive attribute that involves an understanding of the experiences and perspectives of the patient, combined with the capacity to communicate this understanding. ${ }^{4}$ The JSPE was designed primarily with physicians in mind; however, in 2009, the original developers adapted the scale in such 
a way that it could be easily applied, with little methodological difficulty, to students in health professions other than medicine. ${ }^{9}$ In the JSE-HP, 13 items from the medical student version were modified by replacing the term "physician" with the phrase "health care provider". No modification was needed for the other items. The JSE-HP includes no reference to a specific health profession and is particularly suited for use in comparative studies across a range of health professions. ${ }^{2}$ In the context of the present research study, this was particularly beneficial as it negated the need for developing and piloting an appropriate tool; the JSE-HP was therefore deemed an appropriate tool for ongoing research purposes.

The JSE-HP is a 20 -item psychometrically valid measurement of empathy that can be completed in 10 minutes. Students rate their level of agreement with each statement on a 7-point Likert scale ( $1=$ strongly disagree, $7=$ strongly agree). Ten of the 20 questions are negatively worded in order to reduce the confounding effect of acquiescence responding, which were later reverse scored for analysis. ${ }^{22}$ JSE-HP scores range from a minimum of 20 through to a maximum of 140, with a higher score indicating that the student has a tendency to engage more empathically in the context of patient care.

Evidence of the scales' reliability and validity has been previously documented. ${ }^{3,22,23}$ Test-retest reliability coefficients for 3- to 4-month intervals between completion of the JSPE was 0.65 among physicians,${ }^{24}$ and its construct validity and dimensionality was confirmed using factor analysis among medical students, residents, physicians, and nurses. ${ }^{24,25}$

In their own study to determine the psychometric properties of the JSE-HP, the developers found that the scale had an internal consistency of 0.78 , as measured by Cronbach's alpha for the 20 items, which falls within the generally agreed standard of 0.7 or above. ${ }^{2,26}$ The test-retest reliability coefficient was 0.58 for 99 students who completed a second empathy scale within a 3-month period and 0.69 for 30 students who completed the JSE-HP a second time within 6 months. ${ }^{2}$

\section{Procedures}

At the conclusion of lectures for each year level of each of the three undergraduate courses, students were invited to participate in the study. Students were provided with an explanatory statement and were informed that participation was voluntary and anonymous. A nonteaching member of staff facilitated the process and students were administered a questionnaire containing the demographic and JSE-HP questions.
The questionnaire took approximately 10 minutes to complete and consent on the part of the students was implied by its completion. All data were deidentified and analyzed on a group basis. Because convenience sampling was used, no data were available on those students who declined to participate, nor could we track students over the three years due to ethical and privacy reasons. Thus, all data analyses are reported as aggregate only.

\section{Statistical analysis}

The Statistical Package for Social Sciences (SPSS version 19.0; IBM Corporation, Armonk, NY, USA) was used for data storage, as well as for tabulation and generation of descriptive statistics. The latent constructs (factors) produced by the JSE-HP are derived from Likert-style scales and are therefore considered ordinal-level data; they are, however, analogous to continuous data and are normally distributed, allowing the data to be treated as interval-level data. ${ }^{27}$ As such, means were used to describe the data and one-way analyses of variance (ANOVA) were used to explore relationships between demographic variables and empathy. Cases with missing data were excluded from the analyses. The effect sizes (Cohen's $d$ ) were calculated to evaluate the findings, and results are considered statistically significant if the $P$-value is $<0.05$. Post hoc comparisons were performed using Sidak's correction test.

\section{Results}

\section{Demographics}

A total of 948 students participated in the study, and the full demographic data are reported in Table 1. There was a disproportionally high number of female students $(84.7 \%)$ and the majority of students were aged $<21-25$ years old. Students from each year level of each course were recruited to ensure that the sample included a representative cross-section of the entire student body enrolled in the three degree courses. Emergency health (paramedic), nursing, and midwifery are all 3-year courses.

\section{Analyses at item level}

Participants used the full range of responses for each item (1-7) and JSE-HP mean scores ranged from a modest score of 4.18 (standard deviation [SD] $=1.54$ ) for the question, "I do not allow myself to be influenced by strong personal bonds between my patients and their family members" to a high of 6.29 ( $\mathrm{SD}=1.18$ ) for the question, "I believe that emotion has no place in the treatment of medical illness". JSE-HP item SDs ranged from 1.17-2.19. 
Table I Demographic variables of 948 first-, second-, and thirdyear students of Monash University, 2008-2010

\begin{tabular}{lll}
\hline & Number & Percentage \\
\hline Course enrolled in & & \\
Emergency health (paramedics) & 349 & 36.9 \\
Nursing & $4 I 1$ & 43.4 \\
Midwifery & 188 & 19.7 \\
Total & 948 & 100 \\
Year of course & & \\
First year & 253 & 26.7 \\
Second year & 405 & 42.8 \\
Third year & 288 & 30.4 \\
Missing/not reported & 2 & 0.2 \\
Total & 948 & 100 \\
Student age group & & \\
$<21$ years & 344 & 36.3 \\
2I-25 years & 297 & 31.3 \\
26-30 years & 104 & 11.0 \\
3I-35 years & 76 & 8.0 \\
36-40 years & 72 & 7.6 \\
4I-45 years & 44 & 4.6 \\
$>45$ years & $1 \mathrm{I}$ & 1.2 \\
Total & 948 & 100 \\
Sex & & 84.2 \\
Female & 798 & 15.2 \\
Male & 144 & 0.6 \\
Missing/not reported & 6 & 100 \\
Total & 948 & \\
\hline
\end{tabular}

Questions such as "My patients feel better when I understand their feelings" (mean $=6.07, \mathrm{SD}=1.29$ ) and "Patients" illnesses can be cured only by medical or surgical treatment; therefore, emotional ties to my patients do not have a significant influence on medical or surgical outcomes" ( $M=6.04$, $\mathrm{SD}=1.32$ ) recorded higher scores. The lower scoring items included the questions, "Asking patients about what is happening in their personal lives is not helpful in understanding their physical complaints" $(M=4.31, \mathrm{SD}=2.19)$ and "I try to think like my patients in order to render better care" $(M=4.78, \mathrm{SD}=1.51)$.

\section{Course, sex, and age differences}

Emergency health (number $[n]=349)$, nursing $(n=411)$, and midwifery $(n=188)$ students were compared on their empathy scores. Midwifery students' mean score $(M=108.98$, $\mathrm{SD}=17.2$ ) was higher than those for emergency health $(M=104.41, \mathrm{SD}=14.9)$ and nursing students $(M=103.92$, $\mathrm{SD}=14.4$ ) (see Table 2). A one-way ANOVA was conducted to explore the impact of course on levels of empathy, as measured by the JSE-HP. There was a statistically significant difference at the $P<0.05$ level in empathy scores between the three undergraduate courses, $F_{(2,945)}=7.74, P<0.0001$.
Table 2 Group comparisons on mean empathy scores and SDs on the total scores on the Jefferson Scale of Empathy-Health Professional of 948 first-, second-, and third-year students of Monash University, 2008-2010

\begin{tabular}{|c|c|c|c|}
\hline & Mean & SD* & $\begin{array}{l}\text { Statistic (group } \\
\text { difference) }\end{array}$ \\
\hline \multicolumn{4}{|l|}{ By sex } \\
\hline Female $(n=798)$ & 106.2 & 14.8 & $P=0.635$ \\
\hline Male $(n=144)$ & 100.6 & 14.4 & \\
\hline \multicolumn{4}{|l|}{ By age } \\
\hline$<21$ years $(n=344)$ & 104.8 & 13.1 & $P=0.001$ \\
\hline $21-25$ years $(n=297)$ & 103.8 & 17.5 & \\
\hline $26-30$ years $(n=104)$ & 108.5 & 11.4 & \\
\hline $31-35$ years $(n=76)$ & 108.2 & 14.8 & \\
\hline $36-40$ years $(n=72)$ & 104.6 & 18.0 & \\
\hline $4 I-45$ years $(n=44)$ & 100.3 & 17.7 & \\
\hline$>45$ years $(\mathrm{n}=\mathrm{II})$ & 117.5 & 8.2 & \\
\hline \multicolumn{4}{|l|}{ By study year } \\
\hline $2008(n=276)$ & 107.3 & 15.4 & $P<0.000 \mathrm{I}$ \\
\hline $2009(n=396)$ & 102.0 & 14.6 & \\
\hline $2010(n=276)$ & 107.3 & 15.4 & \\
\hline \multicolumn{4}{|l|}{ By course type } \\
\hline Emergency health $(n=349)$ & 104.4 & 14.9 & $P<0.0001$ \\
\hline Nursing $(n=4 I I)$ & 104.0 & 14.4 & \\
\hline Midwifery $(n=\mid 88)$ & 109.0 & 17.2 & \\
\hline \multicolumn{4}{|l|}{ By year level } \\
\hline First year $(n=253)$ & 103.8 & 16.8 & $P=0.071$ \\
\hline Second year $(n=405)$ & 106.5 & 13.3 & \\
\hline Third year $(n=288)$ & 104.0 & 16.3 & \\
\hline
\end{tabular}

Note: *Rounded to one decimal place.

Abbreviations: SD, standard deviation; n, number.

Post hoc comparisons using Sidak's correction test confirmed that the mean score for midwifery students was significantly different at the $P<0.05$ level from emergency health (paramedic) and nursing students. Despite reaching statistical significance, however, the magnitude of the differences in mean scores between midwifery and emergency health and nursing students using Cohen's $d$ were small at 0.28 and 0.32 , respectively, and considered of negligible practical importance.

Women $(n=798)$ and men $(n=144)$ were compared on their empathy scores. Women's mean score $(M=106.2, \mathrm{SD}=14.83)$ was higher than men's $(M=100.6, \mathrm{SD}=14.41)$. Using Levene's test for equality of variances, the sex difference was not statistically significant $\left(t_{[1,936]}=2.05, P=0.635\right)$. The effect of the difference in the means (mean difference $=5.64$ ) using Cohen's $d$ was 0.39 , which approaches moderate practical importance.

Compared by age, students in the age range of 26-30 years and 31-35 years recorded higher empathy scores than their younger colleagues aged $<21$ years and $21-25$ years, 
and the difference in mean scores was found to be statistically significant at the $P<0.05$ level: $F_{(6,939)}=3.83, P<0.001$. Although the 12 students in the $>45$ years category scored highest $(M=117.50, \mathrm{SD}=8.23)$, they represent only $1.3 \%$ of the overall sample, and as such, the data were not regarded as being especially insightful. Using Sidak's correction test, post hoc comparisons indicated that there was no significant difference between those who were 26-30 years $(M=108.46$, $\mathrm{SD}=11.38)$ and $31-35$ years old $(M=108.20, \mathrm{SD}=14.76)$, and between those aged $<21$ years $(M=104.83, \mathrm{SD}=13.13)$ and $21-25$ years $(M=103.82, \mathrm{SD}=17.52)$.

\section{Other group differences}

When compared by year level, students in the second $(M=106.50, \mathrm{SD}=13.03)$ and third $(M=104, \mathrm{SD}=16.34)$ years of study reported higher empathy scores than their counterparts in the first year $(M=103.82, \mathrm{SD}=16.80)$, but the difference was not statistically significant $(P=0.071)$.

The results for study year $(2008,2009,2010)$ show a decline from an average mean of $107.32(\mathrm{SD}=0.929)$ in 2008 to 102.02 ( $\mathrm{SD}=0.732$ ) in 2009 before rising to 107.32 again in 2010. In post hoc comparisons, the differences were statistically different $(P<0.0001)$, but the effect size was small $(d=0.35)$ and considered of negligible practical importance.

\section{Discussion}

The findings demonstrate that female students reported a higher mean JSE-HP empathy score compared with male students, although it did not reach statistical significance in our study. This result is consistent with those of other studies, ${ }^{19,28,29}$ where women consistently recorded higher empathy scores. For example, female medical students at one United Kingdom university were found to be more empathic compared with males and scored a significantly higher mean $(M=5.55, \mathrm{SD}=0.46)$ than the male students $(M=5.35$, $\mathrm{SD}=0.55)$ on the JSPE scale. ${ }^{30}$ The results of a Japanese study also revealed a higher JSPE mean score among female medical students $(M=107, \mathrm{SD}=11.1)$ than males $(M=103.7$, $\mathrm{SD}=13.2$ ), and found the sex difference to be statistically significant $\left(t_{[376]}=2.2, P=0.02\right) .{ }^{26}$

While the results of our study should be viewed in the context of two professions (nursing and midwifery, which are traditionally dominated by women), ${ }^{31}$ they fall short of providing an explanation for sex differences in empathy. It is unclear if the differences are due to (internal) evolutionary or (external) sex role factors, or because female health professionals possibly spend more time with patients and practice more patient-centered care. Another reason could be the way that nursing and midwifery students are educated or the type of practice education experiences they have. Recent work by Penprase et $\mathrm{al}^{31}$ found that male student nurses have higher empathy levels than males from the general student population, and that this plays an important part in attracting males to the nursing profession. Despite these findings from Penprase et al, ${ }^{31}$ further empirical research in this area is needed.

Mean empathy scores for this cohort of undergraduate health science students are lower than the scores reported in other studies that have used the JSE-HP. There are no previously reported studies of empathy among emergency health and midwifery students using the JSE-HP, and it is therefore difficult to benchmark their scores. Previous studies of nurses using the JSPE reported empathy scores of 117 and $124,,^{32,33}$ and in another study where a different version of the scale that was specifically adapted for nursing was used, a mean of 114 was reported. ${ }^{34}$ For comparative purposes, doctors in training typically present with scores in the range of $115-118,35,36$ and people-oriented specialists such as pediatricians show higher levels of empathy than their more technology-oriented colleagues in radiology or surgery. ${ }^{25,30}$

Even when allowing for the relatively low JSE-HP base scores, the fact that empathy scores improved between the first and third years of study is encouraging at a time when concerns have been raised about the negative impact that professional fieldwork education and academic education are having on students' attitudes. ${ }^{37,38}$ Practice education experience starts in the second year, so first-year nursing and midwifery students would not have been exposed to clinical settings. Such a positive gradation in mean empathy scores indicates that the courses do not appear to have a negative impact on student empathy levels. This finding contrasts with those of other studies of health science and medical courses that have reported a decline in empathy over the course of study. ${ }^{19,39}$

In their study of nurses at one American university, Ward et $\mathrm{al}^{21}$ noted a statistically significant decline in empathy as a result of exposure to clinical encounters. The authors have posed several reasons for this decline: a lack of appropriate role models; negative attitudes from academic staff; an intimidating educational environment; heavy classroom and clinical assignments; and patient negativity. Another area that may contribute to lower empathy levels is the systematization of nursing education, ${ }^{40}$ or in other words, developing a systems approach, being organised and integrating systems based thinking in their work, Penprase et $\mathrm{al}^{40}$ argued that systematization may be affected 
by increasing levels of critical thinking, increased theoretical knowledge, and the authors have also questioned the role that hospital systems play during the clinical placement education. Nursing education, in particular, has been criticized for not providing students with the necessary skills to empathize with their patients once in a clinical setting. ${ }^{13}$

The reporting of no statistical difference between each of the three years across the health professional courses in our study is an important finding, as it suggests the courses do not have a detrimental effect on student empathy. A statistical difference between age and year of study and mean empathy scores may have suggested that empathy levels had only increased across the duration of the course because students had aged. However, that was not the case, which lends weight to the conclusion that the courses are responsible for the students' improvement in mean JSE-HP scores, and it is not simply a result of third-year students having a greater amount of life experience than their colleagues in the first year. Further examination of this point could be investigated using qualitative or mixed methodologies.

The finding of higher empathy scores in 2010 following a dip in 2009 raises more questions than answers as, based on previous research, one might have expected mean scores to decline as students' studies progressed. ${ }^{6}$ It is interesting to speculate the reasons for these results. There was no change in submission policies, nor were there structural changes in the core content of the curriculum across the three courses, and the higher empathy score in 2010 may imply more attention on nontechnical skills including the importance of empathy as a desired attribute in health professionals.

It is important to note, however, that while the health science courses seem to have a positive effect, they do not take mean empathy scores above and beyond those reported for participants in other studies. This suggests that there is considerable room for improvement with a clear need for strategies to improve the acquisition of empathy. Possible measures might include, but are not limited to, role playing, exposure to positive role models, and opportunities for improving narrative skills. These and other changes in nursing education are a way forward to enhance nursing students' understanding of the patient's perspective that will allow the students to engage with patients empathically and, ultimately, improve clinical outcomes. ${ }^{5,21,40}$

The higher empathy scores recorded by midwifery students are interesting - are they a result of the course and differences in structure, staff, and facilities, or are they the result of immersion in the profession? Or are they simply associated with attracting students with higher empathy levels, as suggested by some scholars? ${ }^{31,40}$ Midwifery students undertake 2 days per week in clinical practice during their second and third years and this may have some impact. It may also be explained by the fact that midwifery is different from emergency health and nursing, as midwives care for healthy women, as well as those with underlying medical and physical conditions..$^{41}$ Thus, while students in their clinical practice during the second and third years of study experience difficult situations, they are also exposed to happy occasions. This contrast may be enough to prevent the decline of empathy often reported in medical and other health care students.

The lack of prior research on emergency health (paramedic) students' empathy levels using the JSE-HP makes it difficult to benchmark their empathy scores. Their scores are lower than those found in other health workers, which may be partly explained by their exposure to patient encounters and severe trauma very early in their studies. They often have to deal with severely distressed (for example, car accident) or hostile (for example, substance abuse) patients, situations in which it is especially difficult to establish a positive patient-provider relationship..$^{42}$ These are, however, exactly the situations where an appropriate empathic intervention can make all the difference in effecting behavioral change. As empathy is not formally taught in the undergraduate emergency health program, the integration of an empathy teaching and learning "toolkit", or a greater focus on nontechnical skills in patient simulation laboratories are possible ways forward.

It is important to acknowledge those who suggest that the decline of empathy levels among health profession students, and medical students in particular, has been overexaggerated ${ }^{43}$ and that research on empathy in the health professions is dominated by relatively narrow quantitative methods. ${ }^{44}$ It is therefore recommended that future studies are conducted in tandem with measures of the patient's measure of empathic concern and effective clinical care. This will provide educators with valuable feedback to create a fuller picture and assist planners in the development of appropriately constructed health curricula.

There are several limitations to our study. While the findings provide insights into health students' development of empathy across their period of study, the results cannot be generalized. Given the ethical constraints and convenience sampling, we were unable to control for nonresponse bias and individually track all students over the three years; hence, it is likely that some results may not be representative of the three cohorts. The study was conducted at one Australian 
university, and replication of this longitudinal study across multiple institutions, different cultures, and a variety of health professions is recommended to establish a greater understanding of empathy. While two different versions of the Jefferson Empathy Scale were used in this study, and since the underlying latent constructs and subscales being measured are the same, results over the three years should be considered as equivalent. Further psychometric evaluation of the JSE-HP should be undertaken. It is important to note that while the JSE-HP is especially useful for exploring empathy levels in prospective health care practitioners, future studies should include other essential cognitive attributes such as communication and listening styles. It is all very good to have a strong internal empathic ability, but it is of little use if the practitioner does not have the necessary skills to communicate this understanding to patients. Such research will help identify areas where the curriculum may require strengthening. While three cognate health care professions were compared over time, it is important to highlight the educational differences between each program. For example, there are subtle differences in their curriculum delivery, in the selection and admission processes, and in university entrance scores.

Further research is required in the international context to ensure that the benefits of strong empathic skills are promoted within undergraduate health care curricula, and where low empathy levels are identified for alternative education processes to be explored. Courses need to emphasize the consequences of poor practitioner empathy levels for patients. It is also recommended that longitudinal empathy data be gathered from health professional students enrolled in graduate-entry masters programs, and for these data to be compared and contrasted with those of students enrolled in undergraduate programs. The empathy levels of students enrolled in other health professional courses (for example, optometry, audiology, social work, and pharmacy) could also be explored.

\section{Conclusion}

The findings from this longitudinal study demonstrate that empathy levels for all three courses are relatively stable over the period of study, but that there is room for improvement, particularly among nursing and emergency health (paramedic) students. The relative stability of empathy levels is encouraging and provides a framework for educators to begin constructing guidelines that focus on the need to incorporate, promote, and instill empathy in health students, as recommended by the Association of American Medical Colleges. ${ }^{45}$ By adding to the research base, these findings will provide educators with the opportunity to promote the benefits of empathy in health care curricula and make inroads into reversing the general decline of empathy levels among health care students as reported in the literature.

\section{Acknowledgments}

The Monash University health science students who completed the questionnaires are thanked for their input and insights. The Learning and Teaching Performance FundProjects Grant Scheme of the Monash University Faculty of Medicine, Nursing, and Health Sciences provided funding for completion of this project. Ethical approval was obtained from the Monash University Human Research Ethics Committee.

\section{Disclosure}

The authors report no conflicts of interest in this work.

\section{References}

1. Del Canale S, Louis DZ, Maio V, et al. The relationship between physician empathy and disease complications: an empirical study of primary care physicians and their diabetic patients in Parma, Italy. Acad Med. 2012;87(9):1243-1249.

2. Fields SK, Mahan P, Tillman P, Harris J, Maxwell K, Hojat M. Measuring empathy in healthcare profession students using the Jefferson Scale of Physician Empathy: health provider - student version. J Interprof Care. 2011;25(4):287-293.

3. Hojat M. Empathy in Patient Care: Antecedents, Development, Measurement, and Outcomes. New York, NY: Springer; 2007.

4. Hojat M. Ten approaches for enhancing empathy in health and human services cultures. J Health Hum Serv Adm. 2009;31(4):412-450.

5. Hojat M, Louis DZ, Markham FW, Wender R, Rabinowitz C, Gonnella JS. Physicians' empathy and clinical outcomes for diabetic patients. Acad Med. 2011;86(3):359-364.

6. Hojat M, Vergare MJ, Maxwell K, et al. The devil is in the third year: a longitudinal study of erosion of empathy in medical school. Acad Med. 2009;84(9):1182-1191.

7. Stuart MR, Lieberman JA III, Rakel RE. The Fifteen Minute Hour: Therapeutic Talk in Primary Care. 4th ed. Oxford, NY: Radcliffe Publishing; 2008.

8. Dewi FD, Sudjana G, Oesman YM. Patient satisfaction analysis on service quality of dental health care based on empathy and responsiveness. Dent Res J (Isfahan). 2011;8(4):172-177.

9. Hojat M, Louis DZ, Maxwell K, Markham FW, Wender RC, Gonnella JS. A brief instrument to measure patients' overall satisfaction with primary care physicians. Fam Med. 2011;43(6):412-417.

10. Pollak KI, Alexander SC, Tulsky JA, et al. Physician empathy and listening: associations with patient satisfaction and autonomy. $J \mathrm{Am}$ Board Fam Med. 2011;24(6):665-672.

11. Ahrweiler F, Neumann M, Goldblatt H, Hahn EG, Scheffer C. Determinants of physician empathy during medical education: hypothetical conclusions from an exploratory qualitative survey of practicing physicians. BMC Med Educ. 2014;14:122.

12. Nerdrum P. Maintenance of the effect of training in communication skills: a controlled follow-up. Br J Soc Work. 1997;27(5):705-722.

13. Reynolds WJ, Scott B. Do nurses and other professional helpers normally display much empathy? J Adv Nurs. 2000;31(1):226-234.

14. Konrath SH, O'Brien EH, Hsing C. Changes in dispositional empathy in American college students over time: a meta-analysis. Pers Soc Psychol Rev. 2011;15(2):180-198. 
15. Brunero S, Lamont S, Coates M. A review of empathy education in nursing. Nurs Inq. 2010;17(1):65-74.

16. Dereboy C, Harlak H, Gürel S, Gemalmaz A, Eskin M. [Teaching empathy in medical education]. Turk Psikiyatri Derg. 2005;16(2):83-89. Turkish.

17. Nunes P, Williams S, Sa B, Stevenson K. A study of empathy decline in students from five health disciplines during their first year of training. Int J Med Educ. 2011;2:12-17.

18. Williams B, Sadasivan S, Kadirvelu A, Olaussen A. Empathy levels among first year Malaysian medical students: an observational study. Adv Med Educ Pract. 2014;5:149-156.

19. Chen D, Lew R, Hershman W, Orlander J. A cross-sectional measurement of medical student empathy. J Gen Intern Med. 2007;22(10):1434-1438.

20. Newton BW, Savidge MA, Barber L, et al. Differences in medical students' empathy. Acad Med. 2000;75(12):1215.

21. Ward J, Cody J, Schaal M, Hojat M. The empathy enigma: an empirical study of decline in empathy among undergraduate nursing students. J Prof Nurs. 2012;28(1):34-40.

22. Hojat M, Gonnella JS, Nasca TJ, Mangione S, Vergare M, Magee M. Physician empathy: definition, components, measurement, and relationship to gender and specialty. Am J Psychiatry. 2002;159(9): $1563-1569$.

23. Kane GC, Gotto JL, Mangione S, West S, Hojat M. Jefferson scale of patient's perceptions of physician empathy: preliminary psychometric data. Croat Med J. 2007;48(1):81-86.

24. Hojat M, Gonnella JS, Nasca TJ, Mangione S, Veloski JJ, Magee M. The Jefferson Scale of Physician Empathy: further psychometric data and differences by gender and specialty at item level. Acad Med. 2002;77(Suppl 10):S58-S60.

25. Hojat M, Fields SK, Gonnella JS. Empathy: an NP/MD comparison. Nurse Pract. 2003;28(4):45-47.

26. DeVellis RF. Scale Development: Theory and Applications. London, UK: Sage; 1991.

27. Wright DB. Making friends with your data: improving how statistics are conducted and reported. Br J Educ Psychol. 2003;73(Pt 1): $123-136$.

28. Hojat M, Gonnella JS, Mangione S, et al. Empathy in medical students as related to academic performance, clinical competence and gender. Med Educ. 2002;36(6):522-527.

29. Kataoka HU, Koide N, Ochi K, Hojat M, Gonnella JS. Measurement of empathy among Japanese medical students: psychometrics and source differences by gender and level of medical education. Acad Med. 2009;84(9):1192-1197.

30. Tavakol S, Dennick R, Tavakol M. Empathy in UK medical students: differences by gender, medical year and specialty interest. Educ Prim Care. 2011;22(5):297-303.
31. Penprase B, Oakley B, Ternes R, Driscoll D. Do higher dispositions for empathy predispose males toward careers in nursing? A descriptive correlational design. Nurs Forum. Epub January 3, 2014.

32. Fields SK, Hojat M, Gonnella JS, Mangione S, Kane G, Magee M. Comparisons of nurses and physicians on an operational measure of empathy. Eval Health Prof. 2004;27(1):80-94.

33. Hojat M, Gonnella JS, Mangione S, Nasca TJ, Magee M. Physician empathy in medical education and practice: experience with the Jefferson scale of physician empathy. Seminars in Integrative Medicine. 2003;1(1):25-41.

34. Ward J, Schaal M, Sullivan J, Bowen ME, Erdmann JB, Hojat M. Reliability and validity of the Jefferson Scale of Empathy in undergraduate nursing students. J Nurs Meas. 2009;17(1):73-88.

35. Hojat M, Mangione S, Nasca TJ, Gonnella JS, Magee M. Empathy scores in medical school and ratings of empathic behavior in residency training 3 years later. J Soc Psychol. 2005;145(6):663-672.

36. McMillan LR, Shannon DM. Psychometric analysis of the JSPE nursing student version R: comparison of senior BSN students and medical students attitudes toward empathy in patient care. ISRN Nurs. 2011;2011:726063.

37. Coulehan J. Viewpoint: today's professionalism: engaging the mind but not the heart. Acad Med. 2005;80(10):892-898.

38. Newton BW, Barber L, Clardy J, Cleveland E, O'Sullivan P. Is there hardening of the heart during medical school? Acad Med. 2008;83(3): 244-249.

39. Henry-Tillman R, Deloney LA, Savidge M, Graham CJ, Klimberg VS. The medical student as patient navigator as an approach to teaching empathy. Am J Surg. 2002;183(6):659-662.

40. Penprase B, Oakley B, Ternes R, Driscoll D. Empathy as a determining factor for nursing career selection. J Nurs Educ. 2013;52(4): 192-197.

41. Wylie L, Bryce HGH. The Midwives' Guide to Key Medical Conditions: Pregnancy and Childbirth. Edinburgh, Scotland: Churchill Livingstone; 2008.

42. Williams B, Boyle M, Earl T. Measurement of empathy levels in undergraduate paramedic students. Prehospital and Disaster Medicine. 2013;28(2):145-149.

43. Colliver JA, Conlee MJ, Verhulst SJ, Dorsey JK. Reports of the decline of empathy during medical education are greatly exaggerated: a reexamination of the research. Acad Med. 2010;85(4):588-593.

44. Pedersen R. Empirical research on empathy in medicine-a critical review. Patient Educ Couns. 2009;76(3):307-322.

45. Association of American Medical Colleges [webpage on the Internet]. Medical school objectives project (MSOP). Washington, DC: Association of American Medical Colleges; 2014. Available from: https://www.aamc.org/initiatives/msop. Accessed October 9, 2012.
Advances in Medical Education and Practice

\section{Publish your work in this journal}

Advances in Medical Education and Practice is an international, peerreviewed, open access journal that aims to present and publish research on Medical Education covering medical, dental, nursing and allied health care professional education. The journal covers undergraduate education, postgraduate training and continuing medical education
Dovepress

including emerging trends and innovative models linking education, research, and health care services. The manuscript management system is completely online and includes a very quick and fair peer-review system. Visit http://www.dovepress.com/testimonials.php to read rea quotes from published authors. 